\title{
$>$ Pensando as figurações feministas e o devir-mulher a partir da arte
}

\author{
> Thinking over the feminist figurations and the becoming-woman through art
}

\section{por Jacqueline Amadio de Abreu}

Artista e pesquisadora graduada com láurea acadêmica em Artes Visuais pela Universidade Estadual de Maringá (UEM). Membro do DOBRA - grupo de pesquisa em arte, subjetividade, educação e diferença. E-mail: jacqueline-amadio@hotmail.com. ORCID: 0000-0003-0692-1946

\section{por Roberta Stubs}

Artista, pesquisadora e psicóloga com doutorado em Psicologia com ênfase em arte, gênero e produção de subjetividade pela Universidade Estadual Paulista (UNESP) de Assis. Líder do DOBRA - grupo de pesquisa em arte, subjetividade, educação e diferença. Professora do curso de artes visuais da Universidade Estadual de Maringá (UEM). E-mail: robertastubs@gmail.com. ORCID: 0000-0002-1089-5499.

\section{Resumo}

Este artigo tem como objetivo pensar as figurações feministas e o devir-mulher a partir da arte para refletir sobre subjetividades inventivas. Em seu conteúdo, aborda-se o contexto do lugar da mulher na arte, desde o apagamento das mulheres até a reapropriação desse espaço pelos movimentos feministas. Para refletir sobre a arte, são apresentados os conceitos de devir e de figuração, bem como artistas que dialogam com esses conceitos. Sob o aporte teórico feminista, o trabalho aponta a arte como um meio de resistência na produção de novas narrativas pelas figurações, além de um estado de devir como resistência, desconstrução e reconstrução, e um modo de viver mais libertário por parte das mulheres.

Palavras-chave: Estética feminista. Arte. Devir-mulher. Subjetivação.

\begin{abstract}
This article aims to think over the feminist figurations and the becoming-woman through art, in order to reflect on inventive subjectivities. In its content, women's place in art's context is addressed, from their erasure until their reappropriation by feminist movements. The concepts of becoming and figurations are presented to think over art, as well as artists that dialogue with those concepts. Under the feminist theoretical contribution, the present work features art as a way of resistance in the production of new narratives through figurations, while also recognizing the state of becoming as a means of resistance, a deconstruction and reconstruction process, and ultimately a more liberating way of life by women.
\end{abstract}

Keywords: Feminist Aesthetics. Art. Becoming-woman. Subjectification. 
A mulher que sou

Sente muito

que você tenha tido que fugir de uma guerra que seu nome não seja lembrado nas histórias da família que você tenha endurecido para poder ser ouvida que você tenha apanhado com vara quando não quis subir no cavalo que você e sua mãe sejam tão distantes que seu pai não te escute que você fale pouco para não ter risco de ser interrompida que seu silêncio seja lido como indiferença Sinto muito que você se vista para não ser atacada que só você conheça sua história que tenham te levado a acreditar que ela não precisa ser contada Janaina Matter

\section{O espaço das mulheres na arte}

O apagamento das mulheres na sociedade, na história, na ciência, na literatura e nas artes tem-se dado por um processo histórico patriarcal e misógino que desconsidera as contribuições das mulheres em todas essas áreas. Esse processo de silenciamento vem sendo discutido pelos feminismos, para que nós mulheres possamos nos reapropriar da nossa história, ocupar nosso lugar no mundo, conquistar nossos direitos e inventar novas formas de ser e de existir de maneira mais libertária. Essas movimentações já estão acontecendo.

Notadamente, em fins do século XIX e início do XX, no campo da arte, as mulheres eram muito restritas, pois eram desmotivadas e até proibidas de produzir artisticamente, sendo marginalizadas do contexto cultural artístico e 
dos discursos da história da arte, como nos mostra Claudia Priori. ${ }^{1}$ Quando criavam, elas tinham temas limitados relacionados ao feminino, o que envolvia apenas a arte decorativa, retratos de família e de cenas domésticas. Além disso, tinham lugares restritos para a prática, o que as reduzia ao âmbito doméstico. Mesmo as artistas que extrapolavam o que era imposto, produzindo arte com temas críticos, eram desconsideradas, apagadas e ofuscadas e até roubadas por homens da família ou maridos. Com esse cenário que a autora exibe, é possível evidenciar que a restrição dos temas reverberava também na limitação da produção das mulheres, impedidas de experimentar os processos artísticos com mais liberdade e autonomia.

Dessa forma, os homens dominaram o campo artístico. A autora Linda Nochlin aponta que a metodologia da história da arte não considerava esses contextos, o que gerou a ideia de que só existiam gênios homens no campo da arte. ${ }^{2}$ Limita-se a questão apenas a ter ou não ter grandes mulheres artistas, sem refletir em quais condições os sujeitos se encontravam para ter o mesmo acesso à arte.

Nochlin mostra que a metodologia da história da arte não levava em consideração as instituições e as estruturas sociais que rodeavam o artista, criando uma mitologia da arte. ${ }^{3}$ Nessa mitologia, os artistas homens foram constantemente observados em sua situação de gênio, sendo que esse título provinha de um mérito próprio e de um talento e um esforço puros e advindos unicamente dele, sem influência do meio que o cercava. Esse título de gênio

\footnotetext{
${ }^{1}$ Claudia Priori, "Mulheres e a pintura paranaense: relação entre arte e gênero", 2017, p. 1.

${ }^{2}$ Linda Nochlin, Por que não houve grandes mulheres artistas?, 2016, p. 19.

${ }^{3}$ Ibidem, p. 19-20.
} 
artístico não levava em consideração as instituições, os contextos, a sociedade e a economia que rodeavam o artista, os quais eram tratados apenas como fatores secundários. O talento e as condições de êxito vinham unicamente desse artista, uma verdadeira profecia de automerecimento.

De acordo com Nochlin, esse processo acarretou a crença de que a ausência de grandes mulheres artistas se dá pela falta de êxito próprio, e não pelas condições que as cercam. ${ }^{4}$ Deixam de considerar, por exemplo, a situação das artistas, suas classes sociais, a influência da família etc., citando apenas alguns fatores. Essa desconsideração contribuiu para o apagamento e o desmerecimento das mulheres no campo da arte.

[...] Na realidade, como todos sabemos, as coisas como estão e como estiveram, nas artes, bem como em centenas de outras áreas, são entediantes, opressivas e desestimulantes para todos aqueles que, como as mulheres, não tiveram a sorte de nascer brancos, preferencialmente classe média e acima de tudo homens. A culpa não está nos astros, em nossos hormônios, nos nossos ciclos menstruais ou em nosso vazio interior, mas sim em nossas instituições e em nossa educação, entendida como tudo o que acontece no momento que entramos nesse mundo cheio de significados, símbolos, signos e sinais ${ }^{5}$.

Claudia Priori, que faz sua pesquisa sobre a presença da mulher no campo das artes, com um recorte para o cenário da arte no Paraná, de antemão, afirma que a pouca presença das mulheres na arte paranaense não se dá por falta de talentos, "mas por uma exclusão feminina nas carreiras de formação artística" A pesquisadora afirma que, apesar de poucas, havia mulheres que eram reconhecidas no âmbito artístico, porém elas não eram estimuladas a seguir adiante e a explorar mais esse campo. Enquanto era comum aos homens artistas

\footnotetext{
${ }^{4}$ Ibidem, p. 19.

${ }^{5}$ Ibidem, p. 8-9.

${ }^{6}$ Claudia Priori, Op. Cit., 2017, p. 363.
} 
viajar e estudar arte em outros países, as mulheres não faziam o mesmo. Para elas, era comum desistir ou se restringir ao papel de ensinar as técnicas artísticas nas escolas de arte. Dessa forma, nas palavras de Priori, é possível ver “códigos de uma sociedade patriarcal que renegava às mulheres o exercício da cultura, da criação, da produção e composição do mundo"7.

A pergunta Por que não houve grandes mulheres artistas? nos leva à conclusão, até agora, de que a arte não é a atividade livre e autônoma de um indivíduo dotado de qualidades, influenciado por artistas anteriores e mais vagamente e superficial ainda por forças sociais, mas sim que a situação total do fazer arte, tanto no desenvolvimento do artista como na natureza e qualidade do trabalho como arte, acontece em um contexto social, são elementos integrais dessa estrutura social e são mediados e determinados por instituições sociais específicas e definidas $[\ldots]^{8}$.

Dessa forma, mais uma vez, podemos afirmar o apagamento e, até mesmo, um afastamento das mulheres de participar de sua própria história. As condutas sociais patriarcais direcionaram as mulheres a papéis restritos de mães e donas de casa, impedindo-as de participarem ativamente da cultura e da criação artística. Porém, partindo de uma conscientização coletiva, estamos lutando e tecendo novos caminhos para o acesso das mulheres às redes de criações de vidas mais inventivas e libertárias.

Por muito tempo, na história da pintura, os quadros pintados pelos artistas funcionavam como janelas. Cada quadro em sua moldura era uma janela que exibia o real. Dessa forma, por longas décadas, a arte se pautou na representação de corpos; portanto, tratava-se de um corpo-representação. Nesse âmbito, segundo Roberta Stubs, é importante ressaltar que todos esses anos de história contada pelo patriarcado produziram uma longa tradição iconográfica do corpo

\footnotetext{
${ }^{7}$ Ibidem, p. 365.

${ }^{8}$ Linda Nochlin, Op. Cit., 2016, p. 23-24, grifo do autor.
} 
feminino, sendo este sempre representado sob a ótica do olhar e do desejo masculino. ${ }^{9}$ Essa tradição iconográfica se relaciona com o corpo-representação, que diz respeito ao corpo feminino sempre representado por uma ótica masculina dominante, gerando estereótipos, corpos irreais, imagens que apenas satisfazem o ideal masculino e não dizem respeito a um corpo real nem a um corpo vivido por uma mulher.

As mulheres apareceram na arte por muito tempo como criaturas a serem contempladas pelo olhar masculino, nas palavras de Gabriela de Laurentiis, "adoradas ou odiadas por meio das figuras que as representam"10. Tal modo de representação passa a ser vivido e interiorizado, desdobrando-se em submissão e assujeitamento por parte das mulheres aos padrões de beleza e aos modelos identitários produzidos pelo capitalismo contemporâneo.

Com a arte contemporânea, isso começa a mudar; é aqui que começam a surgir os happenings, as performances e as expressões artísticas que levaram a um deslocamento do corpo-representação para um corpo-experiência, sendo este mais relacionado à autoapresentação por parte das mulheres. Nas palavras de Stubs, "[...] o que entra em cena é o corpo como conceito expandido, que envolve a gestualidade, os fluidos, as marcas e os objetos que inserem esse corpo num contexto social e político"11. Ou seja, se, antes, se pintava uma representação do real, nesse outro momento, o corpo é colocado em cena e em experiência. As artistas começam a usar fluidos corporais como componentes das obras, o corpo

\footnotetext{
${ }^{9}$ Roberta Stubs. A/r/tografia de um corpo-experiência, 2015, p. 133.

${ }^{10}$ Gabriela de Laurentiis, "Fazer e desfazer formas: as imagens do feminino na arte de Louise Bourgeois", 2013, p. 32.

${ }^{11}$ Roberta Stubs. Op. Cit., 2015, p. 95.
} 
se torna ativo nos happenings e performances, é a obra viva. Não é somente falar do corpo, mas falar com o corpo.

A arte, então, que por muito tempo foi negada às mulheres, é um potente instrumento que possibilita a criação de novas histórias. Trata-se de uma força inventiva enquanto resistência. $\mathrm{O}$ uso da arte como potência criativa tece narrativas outras sobre nossa existência e emerge de experiências, lutas, denúncias e vivências que marcam nosso corpo e vida. É para o protagonismo também das mulheres no campo da arte que vamos olhar neste artigo.

Zanele Muholi é uma fotógrafa e artista visual sul-africana, mulher, negra e lésbica. Seu trabalho Isilumo Siyaluma significa Dores menstruais e é uma série de pinturas feitas com sangue menstrual, em um processo de 2006 a 2011. Ela fez impressões desse sangue com seu corpo, usando os dedos ou as genitais como carimbo, e, depois, manipulou digitalmente, formando padrões simétricos que se assemelham à figura de flores e mandalas. As linhas de potência desse trabalho podem ser atribuídas ao modo como a artista usa o sangue do seu corpo, sangue menstrual tão estigmatizado pelo patriarcado, e o expõe com uma nova configuração e sob uma nova narrativa. São suas marcas enquanto experiências vividas que prevalecem.

Dessa forma, é muito potente uma artista mulher criar novas figuras femininas a partir de sua ótica. Trata-se de uma representação com potencial político, pois gera deslocamentos na representação dominante masculina que impera na história da arte. Segundo Luana Saturnino Tvardovskas, romper com 
essas imagens é, então, um gesto político por meio de forças criativas antipatriarcais. ${ }^{12}$
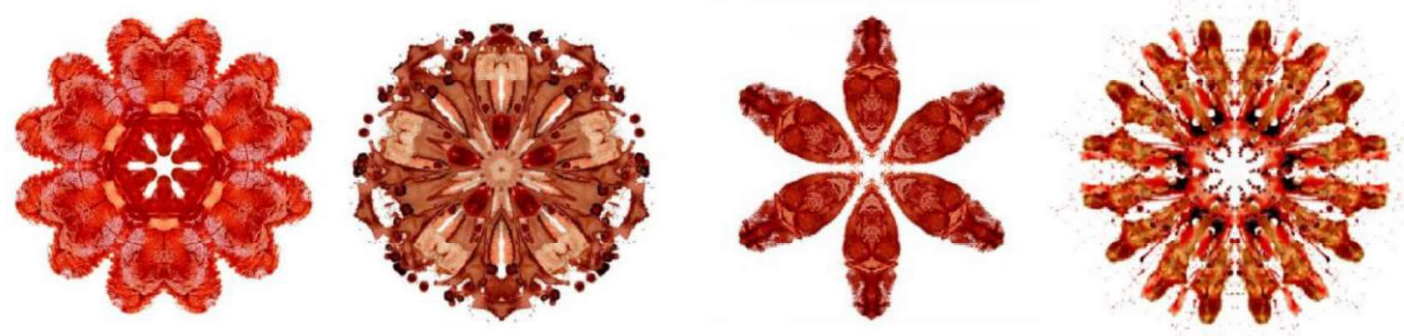

Figura 1

Zanele Muholi, Isilumo Siyaluma, 2006 - 2011, pintura menstrual e manipulação digital.

Sabendo que a tradição iconográfica masculina criou e espalhou imagens de corpos de mulheres pelo viés e pela lógica masculina dominantes, impregnadas de padrões, estereótipos e machismo, é de grande importância a ocupação das mulheres no campo artístico, questionando essas imagens, pondoas em questão. É um trabalho de desconstrução e reconstrução, que cria novas narrativas e apresenta novas visualidades, partindo das experiências e da ótica das mulheres.

${ }^{12}$ Luana Saturnino Tvardovskas, Dramatização dos corpos: arte contemporânea e crítica feminista no Brasil e Argentina, 2015, p. 72. 
A artista gráfica e colagista paranaense Elisa Riemer mostra com seus trabalhos as novas narrativas e visualidades que cria para os corpos das mulheres. Ela faz da sua experiência um motor para criação; coloca em cena o corpo, ou partes desse corpo, como o clitóris, na obra a seguir, e mescla-o com símbolos muito ricos de significações. O corpo e a sexualidade das mulheres, sempre tão silenciados, entorpecidos, sedados e controlados, voltam a vibrar e a celebrar, se deleitam, sentem. Pela arte, há a transformação de narrativas enrijecidas, contadas por bocas e olhares masculinos, em novas narrativas, que emergem da experiência de viver da mulher. $O$ corpo se faz em resistência poética.

No lugar de representação, podemos pensar em uma autoapresentação por parte das próprias mulheres, de seus universos e experiências vividas; portanto, a autoapresentação vai na contramão das representações pelo olhar masculino, que, segundo Ana Gabriela Portelinha Hainosz, “[...] como porta voz da cultura patriarcal e machista, retratavam as mulheres, como belas, recatadas e do lar"13. Desse modo, a autoapresentação é transgressão e deslocamento, as mulheres passam a reivindicar seu direito de representação de si. No lugar de reproduzir e se assujeitar às normas e aos padrões pré-formatados, traçam linhas inventivas de subjetivação, lançando-se em um devir-mulher.

\footnotetext{
${ }^{13}$ Ana Gabriela Portelinha Hainosz, Da representação para a auto apresentação das mulheres nas artes visuais, 2018, p. 30.
} 


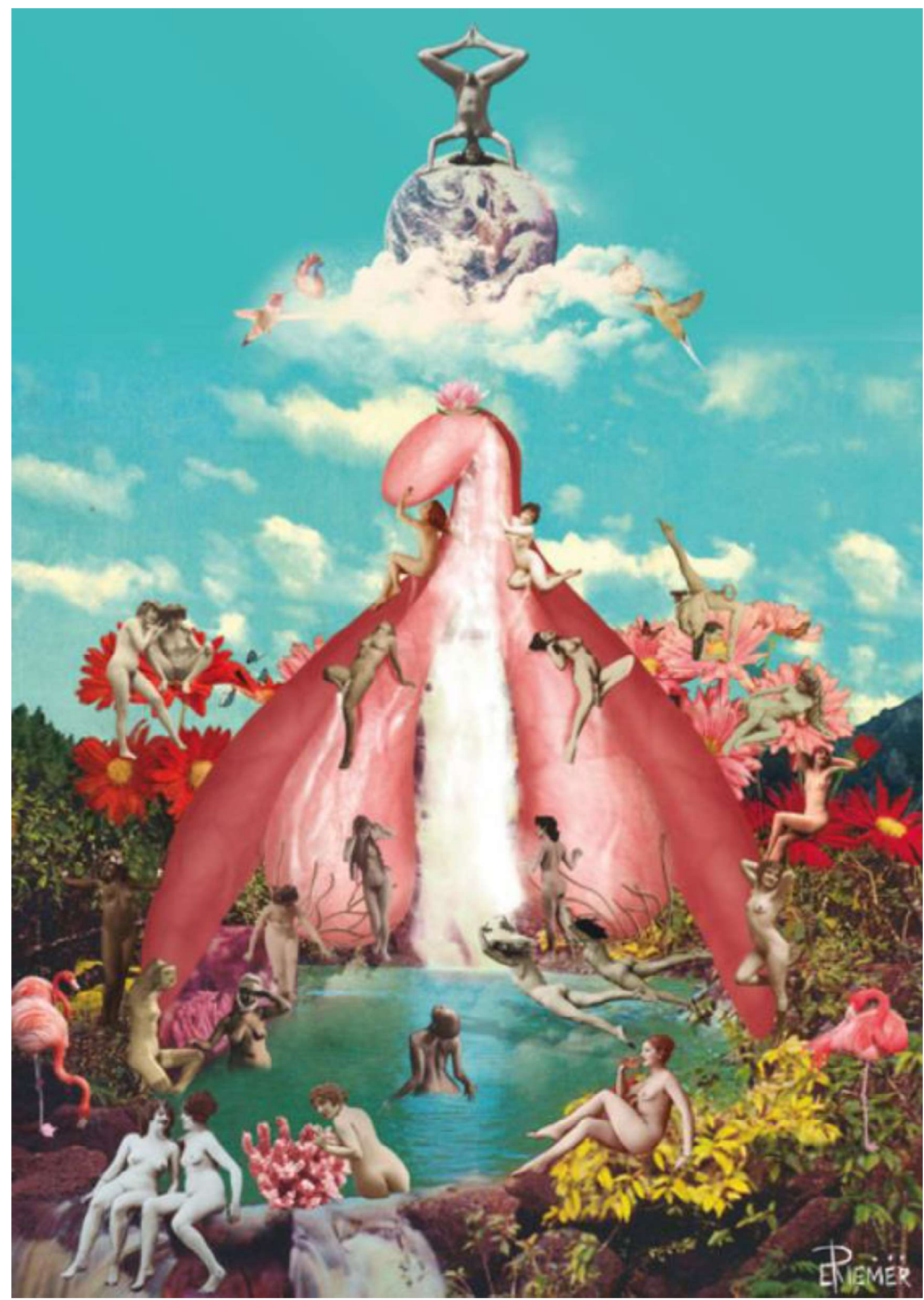

Figura 2

Elisa Riemer, Clítoris, 2017, colagem.

Revista PHILIA | Filosofia, Literatura \& Arte vol. 2, no 2, novembro de 2020 


\section{Devir-mulher}

Ao abordar o contexto em que vivemos e estamos inseridas, desde um período de apagamento até um movimento de reapropriação e reconstrução de narrativas, estamos discutindo a formação de sujeitos e subjetividades. Falar de cultura, de história, de meio é falar de indivíduos, pois todo sujeito afeta e é afetado pelo meio em que vive: modo de pensar, de agir, de ser e de existir. Tratase de formação de sujeito, de processos de subjetivação.

A subjetivação que trataremos aqui é trabalhada por autoras que seguem a perspectiva de Gilles Deleuze e Félix Guattari. Rosane Neves da Silva, partindo de Deleuze, afirma que a subjetividade é entendida como um processo pelo qual se produzem determinados territórios de existência em uma formação histórica específica e que "a subjetivação se refere, portanto, às diferentes formas de produção da subjetividade em uma determinada formação social"14.

As narrativas que se criam em determinada cultura e em determinada época vão se enraizando nos modos de agir, nos modos de vida, e afetando os processos de subjetividade. Essa subjetividade não está dada somente em um movimento interno, até porque, se assim fosse, seria imutável. Além disso, não acontece somente em um acesso ao que é externo, mas sim nessa relação dentro e fora. Segundo Suely Rolnik, "não há subjetividade sem uma cartografia cultural que lhe sirva de guia; e, reciprocamente, não há cultura sem um certo modo de subjetivação que funcione segundo seu perfil. A rigor, é impossível dissociar estas paisagens"15.

\footnotetext{
${ }^{14}$ Rosane Neves da Silva, "A dobra deleuziana: o mundo como potência de invenção", 2004, p. 2.

${ }^{15}$ Suely Rolnik, "Uma insólita viagem à subjetividade: fronteiras com a ética e a cultura", 1997, p. 4.
} 
Pensar nas reverberações desse processo de subjetivação reflete, também, sobre as mulheres na arte: o modo como as formas de ser e de agir são conduzidas socialmente empurra as mulheres para dentro de uma forma muito bem modelada, fechada e limitada, que não comporta as atitudes de desbravamento e experiência que a arte pede. Judy Chicago confirma:

A resposta a todas as perguntas que indagam por que há tão poucas mulheres na arte, portanto, reside exatamente nisto: há tão poucas mulheres artistas porque a estrutura da individualidade da mulher, conforme ditada pela sociedade em que vivemos, é inconsistente com a estrutura da individualidade que é necessária para produzir arte ${ }^{16}$.

Esse processo de subjetivação que resulta do contexto opressor tem sido questionado pelos feminismos, produzindo contínuas desconstruções e conscientizações para que não se repita. É dessa forma que a arte deixou de ser um tema limitado para ser meio de um viver mais libertário, um instrumento que possibilita a voz. Dessa forma, partindo da perspectiva construída pelos feminismos, as narrativas que estamos criando se referem aos modos de subjetivação que dão conta da multiplicidade que envolve o ser mulher.

Temos que pensar que os processos de subjetivação dizem respeito aos modos de existência. Assim sendo, romper com o meio em que vivemos e criar fissuras para novas formas de existência é um método de resistência e uma maneira de viver mais libertária; é uma resposta e uma reação ao que nos é dado. Nessa direção, a arte é impulso, vibração, pulsação de vida, e é instrumento, que objetiva criar-se, escrever-se, pintar-se, inaugurando modos de viver, transformando modos já existentes. Portanto, a arte é devir. Escapamos das formas modeladas de um feminino já moldado e dado como pronto e acabado e

\footnotetext{
${ }^{16}$ Judy Chicago, “A mulher como artista (1971)", 2018, p. 38.
} 
abrimos fissuras para uma não forma, que pode vir a ser o que quisermos nesse campo de um devir-mulher.

Para introduzir esse conceito, Inês Bueno Krahei e Sônia Regina da Luz Matos trazem a perspectiva de Nietzsche: o devir é tudo aquilo que não tem estado final, um estado de variação, “ou seja, [é o estado] de fluidez constante, não havendo espaço para o fixo, o cristalizado, o estático. Assim essa disposição ao inacabado é a possibilidade da invenção de novas formas"17.

Já na perspectiva de Deleuze e Guattari, ainda segundo as autoras, devir é rizoma, é contágio. O devir tensiona a forma, não quer atingir uma configuração permanente e estável, nunca se conclui. Segundo Krahei e Matos, para Deleuze e Guattari, devir-mulher, devir-animal são tendências que dizem respeito a um ser que flui, e nesse fluir se constituem alianças afetivas e rizomáticas com outros, o que faz escapar das políticas de identidade. ${ }^{18}$ Neste artigo, o devir é usado, então, no sentido dado por Deleuze e Guattari: devir como um vir a ser, fluir, transformar; um ponto de partida que abre para infinitas possibilidades de experimentar a vida.

Nos feminismos, encontramos respaldo para pensar um devir-mulher, um modo de ser, habitar, desejar, cultivar e inventar a vida de forma mais livre. Um modo autêntico e ético. Segundo Margareth Rago, o feminismo criou um modo específico de existência, mais humanizado e integrado, desfazendo oposições binárias e hierarquizações, e “inventou eticamente, e tem operado no sentido de renovar e reatualizar o imaginário político e cultural de nossa época"19.

\footnotetext{
${ }^{17}$ Inês Bueno Krahei e Sônia Regina da Luz Matos, "Devir-mulher como diferença", 2010, p. 5.

${ }^{18}$ Ibidem, p. 5.

${ }^{19}$ Margareth Rago, "Feminismo e subjetividade em tempos pós-modernos", 2004, p. 4.
} 
Dentre as suas inúmeras críticas, o feminismo investiu incisivamente contra o sujeito, não apenas tendo como alvo a figura do homem universal, mas visando a própria identidade da mulher. Desnaturalizando-a, mostrou o quanto a construção de um modelo feminino universalizante foi imposta historicamente pelo discurso médico vitoriano, pelo direito, pela família, pela igreja, enfim, pelo olhar masculino reforçado, principalmente nos centros urbanos, pelos estímulos da indústria de consumo. Já são inúmeros os estudos, pesquisas, livros, publicações e revistas que desconstroem as muitas leituras sobre o corpo e a fisiologia da mulher, seus sentimentos, desejos e funcionamentos físicos e psíquicos, subvertendo radicalmente a ordem masculina do mundo, especialmente ao desconectar associação estabelecida entre origem e finalidade, que justificava a definição de uma suposta essência feminina a partir de sua missão para a maternidade ${ }^{20}$.

Ou seja, os feminismos têm atuado de forma inventiva e ética para a criação dos modos de existência; têm transformado e pressionado muitas instituições a reconfigurar os discursos, as narrativas, as maneiras de pensar e de agir, possibilitando uma forma mais humana e ética de se viver. Rosi Marie Santini e Joana Camelier confirmam que a noção de devir-mulher de Deleuze e Guattari atua "como chave para a transformação do que somos, enquanto devirrevolucionário, e para a criação de novos modos de existência"21.

Nessa direção, os processos de subjetivação são mais livres, menos identitários, mais criativos, com mais possibilidades de vida. Segundo Rago, os feminismos têm criado "novos padrões de corporeidade, beleza e cuidados de si, propondo outros modos de constituição da subjetividade, ou o que bem poderíamos chamar de estéticas feministas da existência"22.

Guilherme Castelo Branco, partindo de Michel Foucault, afirma que "talvez se deva entender uma estética da existência como um dos caminhos possíveis,

\footnotetext{
${ }^{20}$ Ibidem, p. 4.

${ }^{21}$ Rosi Marie Santini e Joana Camelier, "Devir mulher, sexualidade e subjetividade: aproximações entre Deleuze \& Guattari e Pierre Bourdieu sobre a construção social dos corpos", 2015, p. 102.

${ }^{22}$ Margareth Rago, Op. Cit., 2004, p. 5, grifo do autor.
} 
dentre outros, pelos quais pessoas realizam estilos de vida não-conformados" ${ }^{23}$. Esse termo foucaultiano, estética da existência, apropriado por Rago como estética feminista da existência, relaciona-se a um modo de ser mulher que resiste e que cria para si novas formas de existir.

Pensando nesses modos de resistência como dispositivo de criação de vida, a arte aparece como um instrumento que possibilita a experiência de uma vida inventiva. O devir é uma porta, uma linha de fuga, e a arte é a matéria que possibilita essa entrada. Branco nos apresenta o termo vida artista, de Foucault. Para o filósofo, essa expressão tem o seguinte sentido:

Designa o trabalho que certas pessoas desenvolvem no sentido de tornar as suas vidas belas, generosas, radiosas, intensas, numa relação com a comunidade de iguais, todos voltados para o desenvolvimento de uma estética da existência, ocupados em fazer da própria vida e da vida de seus próximos uma obra de $\operatorname{arte}^{24}$.

O filósofo acrescenta, ainda, que a vida artista não está vinculada a uma profissão artística, mas se trata de um modo de viver em que cada pessoa tem o cuidado de fazer de suas existências passagens luminosas, experiências inovadoras e formas de vidas belas e intensas, que vão na contramão de modelos dominantes e assujeitados. Nas palavras de Branco, “a vida artista, portanto, é uma possibilidade real para todo sujeito ético, autônomo, com potencial de inventar-se e à vida de outros a ele vinculados"25. O devir-mulher caminha por esse campo que não se conforma com o que já está estabelecido, muito menos

\footnotetext{
${ }^{23}$ Guilherme Castelo Branco, "Anti-individualismo, vida artista: uma análise não-fascista de Michel Foucault", 2009, p. 145.

${ }^{24}$ Ibidem, p. 144.

${ }^{25}$ Ibidem, p. 145.
} 
com as formas de viver moldadas previamente, mas sim com um vir a ser, um experimentar e criar.

Para Deleuze e Guattari, segundo Santini e Camelier, "todos os devires começam e passam pelo devir-mulher"26. O devir-mulher é a abertura e a chave para os outros devires, como a criança, o animal, o vegetal, o mineral, o imperceptível, pois está mais próximo do binarismo do poder fálico, sendo a ordem social fundada pela oposição homem/mulher.

Só depois desta vêm as oposições de classe, de casta, de raça, de nacionalidade, de idade, etc. Portanto, qualquer movimento para fora das estruturas sociais de dominação deve começar pela sexualidade, pela saída do enquadramento dos gêneros e da organização binária dos sexos enquanto motivação ético-política contra a dominação. Ou seja, a questão que se coloca é micropolítica. A saída dos dualismos e das segmentaridades - quaisquer que sejam eles - passa por uma ruptura da sexualização para então alcançar outras rupturas ${ }^{27}$.

Pensar em uma produção de subjetividade inventiva é criar fissuras nos moldes engessados e criar novas maneiras de ser e viver no mundo, ou ressignificar as maneiras já existentes. Nesse contexto, o feminismo possibilitou um modo inventivo, ético e humano de se produzir subjetividade.

O feminismo, tanto enquanto teoria, como enquanto prática, teve e tem uma função social eminentemente política, por seu potencial profundamente subversivo, desestabilizador, crítico, intempestivo, assim como pela vontade que manifesta de tornar o mundo mais humano, livre e solidário, seguramente não apenas para as mulheres. Por tudo isso, não pode recuar diante do enorme desafio que é uma avaliação contínua das próprias subjetividades e dos estilos éticos/estéticos de existência que promove, impedindo a ação das forças reterritorializantes paralizadoras,

\footnotetext{
${ }^{26}$ Rosi Marie Santini e Joana Camelier, "Devir mulher, sexualidade e subjetividade: aproximações entre Deleuze \& Guattari e Pierre Bourdieu sobre a construção social dos corpos", 2015, p. 105.

${ }^{27}$ Ibidem, p. 105.
} 
pois modos feministas de existir só devem se tornar incômodos enquanto movimentos intensos de afirmação da vida ${ }^{28}$.

A arte articulada com o feminismo atua como força política e como um meio de extrapolar essas formas rígidas, abrindo para novos modos de imaginação, para um autoconhecimento e uma experimentação de si, em um fluir devir-mulher. Assim sendo, expandiremos esse diálogo para o conceito de figuração.

\section{Figurações feministas}

Para adentrar nesse assunto, podemos começar com a concepção de imaginação que Rosi Braidotti apresenta, na qual a imaginação é uma prática social e uma zona social disputada, em que atuam também as forças do biopoder, uma vez que há uma busca constante pelo controle do imaginário social, uma disputa da imaginação relacionada aos esgotamentos subjetivos. ${ }^{29}$ É possível citar, também, os feminismos que lutam por esse imaginário em busca de renome e ressignificação positiva. Essa luta pelo imaginário é analisada por Braidotti sob as formas de figurações.

Segundo a autora, "uma figuração não é mera metáfora, mas um mapa cognitivo politicamente informado que lê o presente em termos da situação fixa de alguém" ${ }^{30}$. A figuração é um gesto político, tem intenções e atua na afirmação de formas de vida. O movimento feminista, por sua vez, tem como uma de suas lutas a necessidade de aprender a pensar de maneira diferente sobre a condição histórica da mulher e a necessidade desta de reinventar a si mesma e as relações

\footnotetext{
${ }^{28}$ Margareth Rago, "Feminismo e subjetividade em tempos pós-modernos", 2004, p. 13.

${ }^{29}$ Rosi Braidotti, "Diferença, diversidade e subjetividade nômade", 2002, p. 9.

${ }^{30}$ Ibidem, p. 9.
} 
com o mundo. É um projeto transformador que começa na “[...] renúncia aos hábitos de pensamentos historicamente estabelecidos que, até agora, têm fornecido a visão padrão da subjetividade humana"31.

Tvardovskas também contribui com o tema das figurações afirmando que

Uma figuração feminista é, a meu ver, fruto de uma imaginação feminista e teria o potencial e a tarefa de levar a cabo essa desestabilização das identidades, contribuindo para a criação de novos imaginários e de novos sentidos para o espaço público, assim como os de investir na construção de subjetividades mais libertárias e filóginas ${ }^{32}$.

Podemos pensar, então, na arte e nas figurações feministas como um modo de criar uma história crítica e de combate ao patriarcado pela imagem e pela imaginação; imaginação essa como exercício político.

Icleia Borsa Cattani propõe que “a obra de arte é da ordem da apresentação e não, da representação" ${ }^{33}$, sendo que a apresentação não faz referência a um já dito, mas sim ao dizer em si. Cattani afirma, ainda, que os corpos das artistas estão presentes nas obras por vestígios e por todo corpo a corpo e embates que constituem essas obras ${ }^{34}$.

Os corpos das artistas imprimem em suas obras todas as experiências contidas em seu receptáculo de vida, sejam obras em que a superfície e o instrumento de arte são o próprio corpo ou obras em que o corpo se apresenta por vestígios. Os corpos estão sempre presentes, pois são produções artísticas que

\footnotetext{
${ }^{31}$ Ibidem, p. 9, grifo do autor.

${ }^{32}$ Luana Saturnino Tvardovskas, Figurações feministas na arte contemporânea: Márcia X., Fernanda Magalhães e Rosângela Rennó, 2008, p. 12.

${ }^{33}$ Icleia Borsa Cattani, Icleia Cattani, 2004, p. 115.

${ }^{34}$ Ibidem, p. 115.
} 
partem desse corpo-experiência, dessa arte-vida, partem não só de uma ótica feminina, mas de um devir-mulher de todo o corpo-sensação.

Ana Mendieta (1948-1985) imprimiu todo seu corpo-sensação-emoção em suas produções arte-vida. Ela foi uma artista cubana, que viveu nos Estados Unidos; suas obras expressam devir em um encontro arte-vida-experiência de forma muito potente. Em sua série Siluetas, composta por mais de cem obras, a artista buscou imprimir seu corpo nas mais diversas paisagens e superfícies: chão, água, areia, terra batida, vegetação. Em algumas obras, ela cavava e tingia de tinta ou até queimava algumas dessas silhuetas. Flávia Leme de Almeida apresenta uma fala de Mendieta em que a artista diz: "sinto-me tomada pela sensação de ter sido arrancada do útero (a natureza). A arte é a forma pela qual restabeleço minhas ligações com o universo. É um retorno à origem maternal" 35 .

O corpo-experiência diz mesmo sobre esse corpo sensível, corpo que se abre ao mundo, corpo que não se permite o embrutecimento, pois sabe que pode mais, que vai além, que é intenso e que as possibilidades de vidas e de existências são tantas que mal cabem em si, transbordam. Nas palavras de Stubs, é "corpo enquanto território de vida"36.

\footnotetext{
${ }^{35}$ Flávia Leme de Almeida, Mulheres recipientes: recortes poéticos do universo feminino nas artes visuais, 2010, p. 112.

${ }^{36}$ Roberta Stubs, Devires de um corpo experiência, 2019, p. 113.
} 


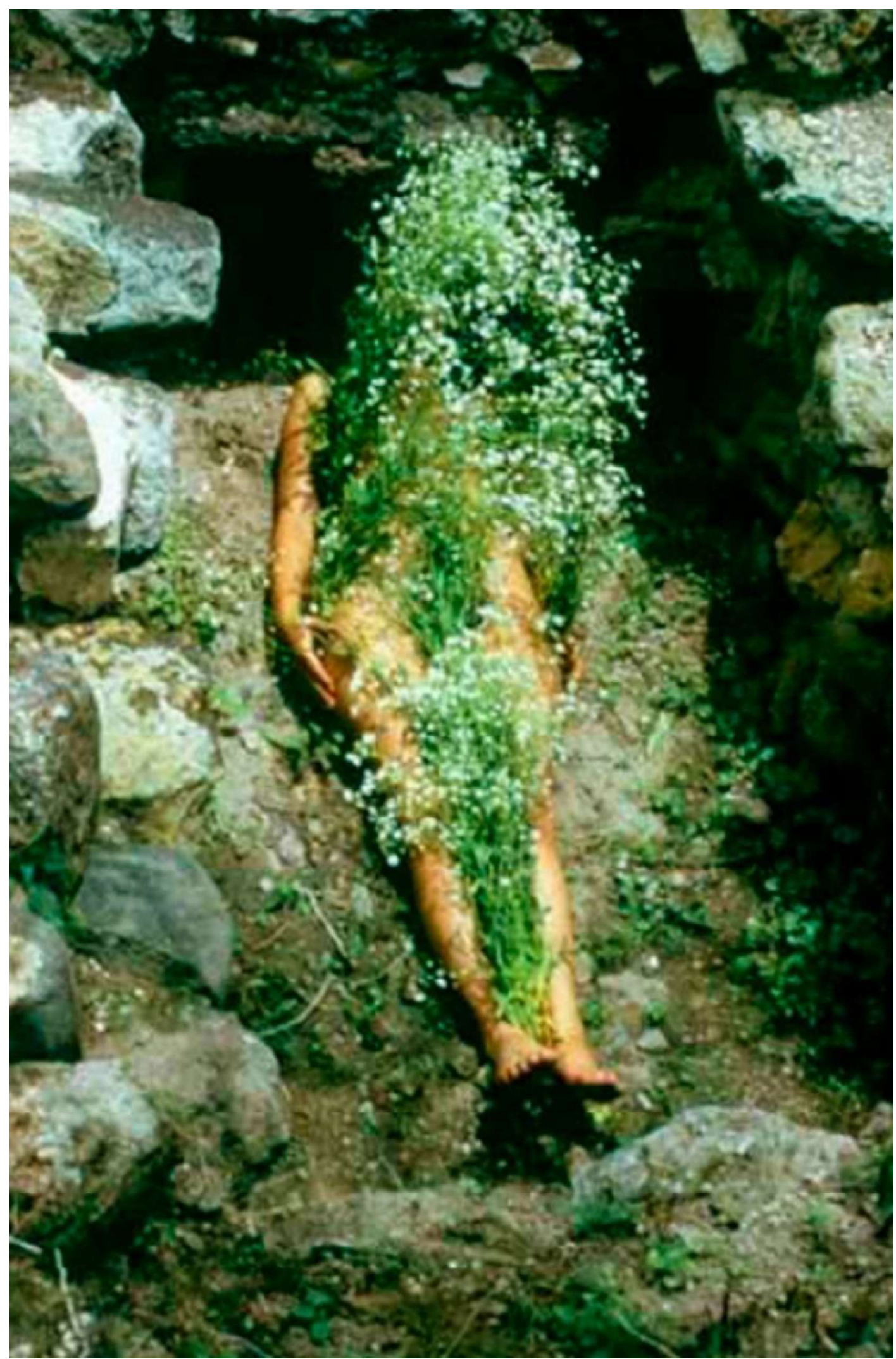

Figura 3

Revista PHILIA | Filosofia, Literatura \& Arte vol. 2, no 2, novembro de 2020 
As artistas, ao usarem seu corpo-experiência como disparador para suas produções, criam imagens artísticas impregnadas de uma estética feminista sobre os corpos, as experiências e as vidas de mulheres. É o que podemos chamar, também, de prática autobiográfica, que, segundo Laurentiis, é "uma narratividade constituída pelo retrato da experiência vivida [que] aparece como exposição da própria ficção da identidade e do autor" ${ }^{37}$. É a prática autobiográfica como criação artística de um outro si, uma forma de resistência aos assujeitamentos e aos modos de capturas de subjetivação.

Na dimensão da arte, as práticas autobiográficas das feministas ironizam os discursos patriarcais. Elas fazem de sua experiência como mulher motor para a criação, recorrendo às figuras nas quais fundam a identidade feminina e, consequentemente, as suas próprias ${ }^{38}$.

Segundo Tvardovskas, a arte contemporânea pode ser mais bem compreendida na interseção com as estéticas da existência, ao reivindicar espaços de liberdade e de resistência partindo da imaginação. ${ }^{39} \mathrm{O}$ termo estéticas da existência é usado para designar certo modo de produção artística, a fim de fugir de uma possível armadilha identitária. De acordo com Stubs, o conceito pode ser usado independente de estar ou não ligado aos movimentos feministas e possui ainda uma "força inventiva/afirmativa enquanto estratégia ética/estética/política de subversão, resistências e criação de possibilidades de vida"40. Esse termo possui ainda como característica “[...] um elo indissociável

\footnotetext{
${ }^{37}$ Gabriela de Laurentiis, "Fazer e desfazer formas: as imagens do feminino na arte de Louise Bourgeois", 2013, p. 32.

${ }^{38}$ Ibidem, p. 33.

${ }^{39}$ Luana Saturnino Tvardovskas, "Fabulações de si na arte contemporânea: Ana Miguel, Rosana Paulino e Cristina Salgado", 2013, p. 181.

${ }^{40}$ Roberta Stubs, $A / r /$ tografia de um corpo-experiência, 2015, p. 168.
} 
entre arte e vida, entre arte e experiência, entre arte e produção de subjetividade" ${ }^{41}$.

A experiência que ela [a arte] promove é capaz de intervir no processo de subjetivação daqueles que dela se aproximam, precisamente no ponto em que o desejo tende a tornar-se cativo e a despontencializar-se. Quando isso acontece, reanima-se o exercício do pensamento e ativam-se outras formas de percepção, mas também e, sobretudo, de invenção e de expressão. Delineiam-se novas políticas do desejo e sua relação com o mundo - ou seja, novos diagramas do inconsciente das forças que desenham mapas cuja tendência é mutilar a vida em seu próprio âmago o qual consiste, como vimos, em sua insistência em reciclar-se na recriação permanente do mundo ${ }^{42}$.

Dessa forma, a arte associada à estética feminista da existência e aos feminismos pode ser capaz de produzir figurações que deslocam as imagens enrijecidas. Criam-se, a partir de uma imaginação inventiva, novas figuras de existência, que brotam de um corpo-experiência, que pulsa e vive de forma mais livre. Refaz-se, assim, o imaginário feminino por meio das criações feitas por mulheres, saindo de um molde feminino e indo para as possibilidades do devirmulher. Esse modo de resistência pela arte

elabora, assim, um repertório imagético em ressonância com as lutas feministas contra a cultura patriarcal, simultaneamente, recuperando e desestabilizando as representações estabelecidas do feminino. Escava o passado, questiona o presente, desmascara as tecnologias de poder investidas em seu corpo. Ela alude às potentes e resistentes mulheres esquecidas pela história ${ }^{43}$.

Uma artista que pode ser citada aqui com um trabalho potente que desloca imagens é a norte-americana Judy Chicago, com a grandiosa instalação The dinner party. Nessa obra, a artista se reapropria das imagens para reinventar um

\footnotetext{
${ }^{41}$ Ibidem, p. 169.

${ }^{42}$ Suely Rolnik, Arquivo para uma obra acontecimento, 2011, p. 27.

${ }^{43}$ Gabriela de Laurentiis, "Fazer e desfazer formas: as imagens do feminino na arte de Louise Bourgeois", 2013, p. 34.
} 
imaginário e recuperar nomes esquecidos e deixados para trás na história, dentro de uma estética feminista. Essa obra foi composta por pratos de cerâmica pintados à mão, como um meio de representação simbólica da exclusão de muitas mulheres na história. A artista pensou em uma releitura da Última Santa Ceia sobre o ponto de vista da mulher que só servia a mesa. Ela usou uma mesa triangular com treze pratos em cada lateral, representando, de forma simbólica, 39 mulheres. Além disso, todo o piso que sustentava a mesa foi composto por triângulos de cerâmica esmaltados que possuíam 999 nomes de mulheres relevantes na história, seja no meio mitológico, religioso, artístico, literário, musical, teatral, dentre outros, como descreve Almeida. ${ }^{44}$

Chicago, então, refaz uma cena consagrada no campo religioso sendo protagonizada por mulheres. Além de provocar esse deslocamento, ela recupera nomes e histórias de mulheres fortes, dando visibilidade a esses nomes que foram ignorados e apagados da história. Ao fazer essa retomada de mulheres para recontar uma história, ela gera linhas de subjetivação que possuem o protagonismo das mulheres.

Ao passar pelo território das figurações, não podemos deixar de falar da figuração nômade de Rosi Braitotti. Primeiramente, vale ressaltar que estamos falando a partir da concepção de sujeito devir, que se faz pela construção e pela desconstrução constante de si em relação ao mundo. Subjetividade nômade, segundo a autora, se insere, então, em eixos de diferenciação, como classe, raça, etnia, gênero, idade, dentre outros, que interagem entre si na constituição da subjetividade; "a noção de nomadismo se refere à ocorrência simultânea de

\footnotetext{
${ }^{44}$ Flávia Leme de Almeida, Mulheres recipientes:recortes poéticos do universo feminino nas artes visuais, 2010, p. 107.
} 
muitos deles de uma vez. Subjetividade nômade tem a ver com a simultaneidade de identidades complexas e multicamadas" ${ }^{45}$.

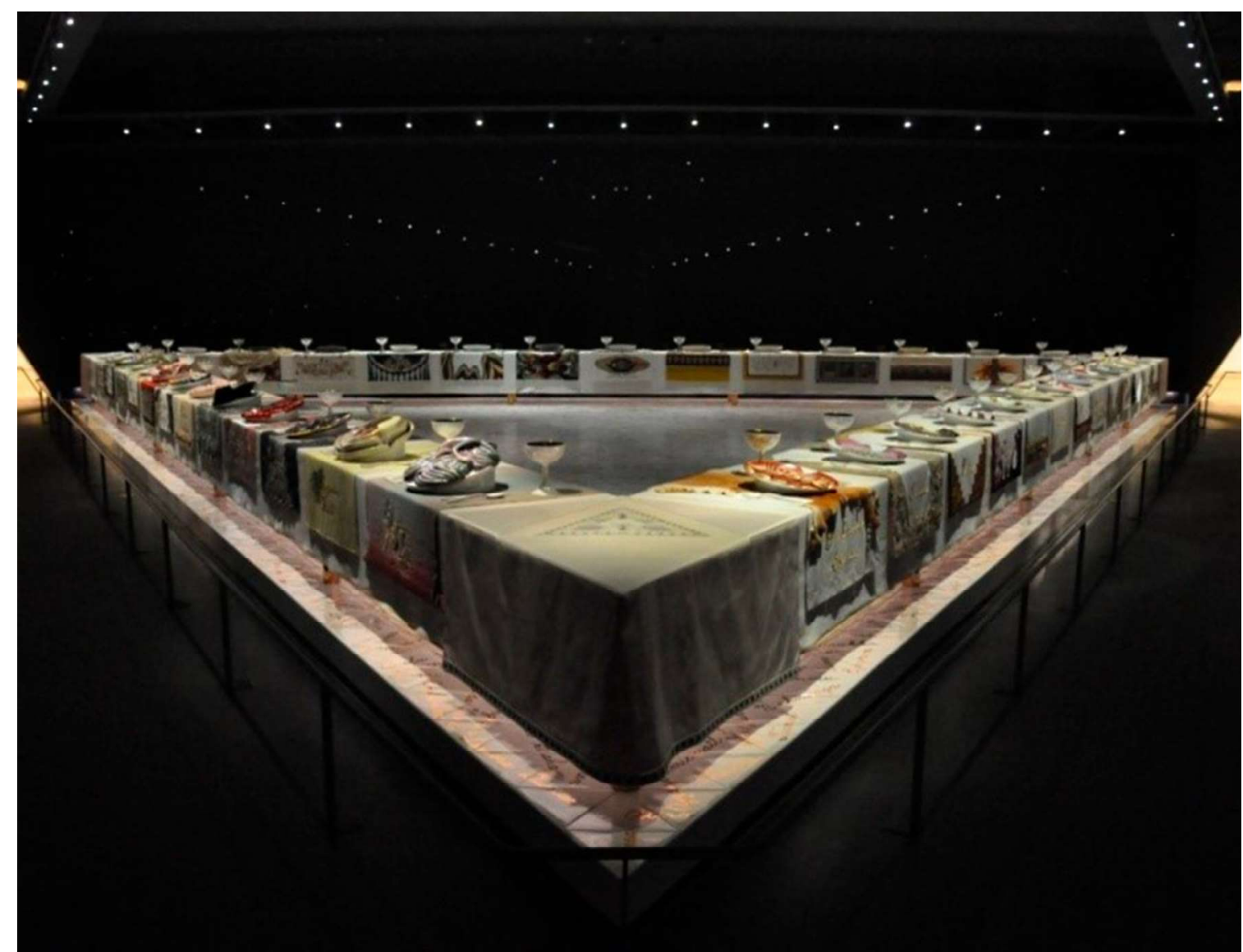

Figura 4

Judy Chicago, The dinner party, 1974-1979, instalação.

O nômade é uma ficção política que permite pensar e se mover por níveis de experiência. Braidotti afirma que a escolha dessa figuração se dá por acreditar na relevância da imaginação e que “ficções políticas podem ser mais efetivas, aqui

${ }^{45}$ Rosi Braidotti, “Diferença, diversidade e subjetividade nômade”, 2002, p. 9-10, grifo do autor. 
e agora, do que sistemas teóricos" ${ }^{46}$ e que a escolha de uma figura como o sujeito nômade é “consequentemente um passo contra a natureza estabelecida e convencional do pensamento teórico e especialmente filosófico" ${ }^{47}$. Ou seja, a ficção política nos dá autonomia e autoria e permite, ainda, reficcionalizar aquilo que já está dado. O nômade tem um tipo de consciência crítica que não se permite fixar.

O nomadismo refere-se ao tipo de consciência crítica que resiste ajustar-se aos modos de pensamento e comportamento codificados. É a subversão do conjunto de convenções que define o estado nômade, não o ato literal de viajar $^{48}$.

A imaginação como exercício político por meio da figuração nômade promove o deslocamento de identidades fixas, resultando em um salto subjetivo que é também um empoderamento pessoal e uma mobilização coletiva, “[...] o viajante nômade é unicamente empenhado no ato de ir, de atravessar" ${ }^{49}$.

Nós, autoras deste artigo, nos reconhecemos como nômades, e é desse lugar que uma de nós pede licença para se apresentar também como artista e experimentadora. Com ousadia, gostaria de compartilhar com vocês um de meus trabalhos em pintura, colocando-me dentre as artistas aqui citadas, pois entendo que elas me compõem, estão em mim e estão presentes antes e durante meu processo de criação. Essa pintura é uma dentre várias experimentações que fiz explorando como o corpo se colocava em meus trabalhos. Nela, o corpo está presente justamente em sua ausência e em sua não representação. Na verdade, o corpo se faz presente por fragmentos, pistas e vestígios.

\footnotetext{
${ }^{46}$ Ibidem, p. 10.

${ }^{47}$ Ibidem, p. 10.

${ }^{48}$ Ibidem, p. 10.

${ }^{49}$ Ibidem, p. 14.
} 


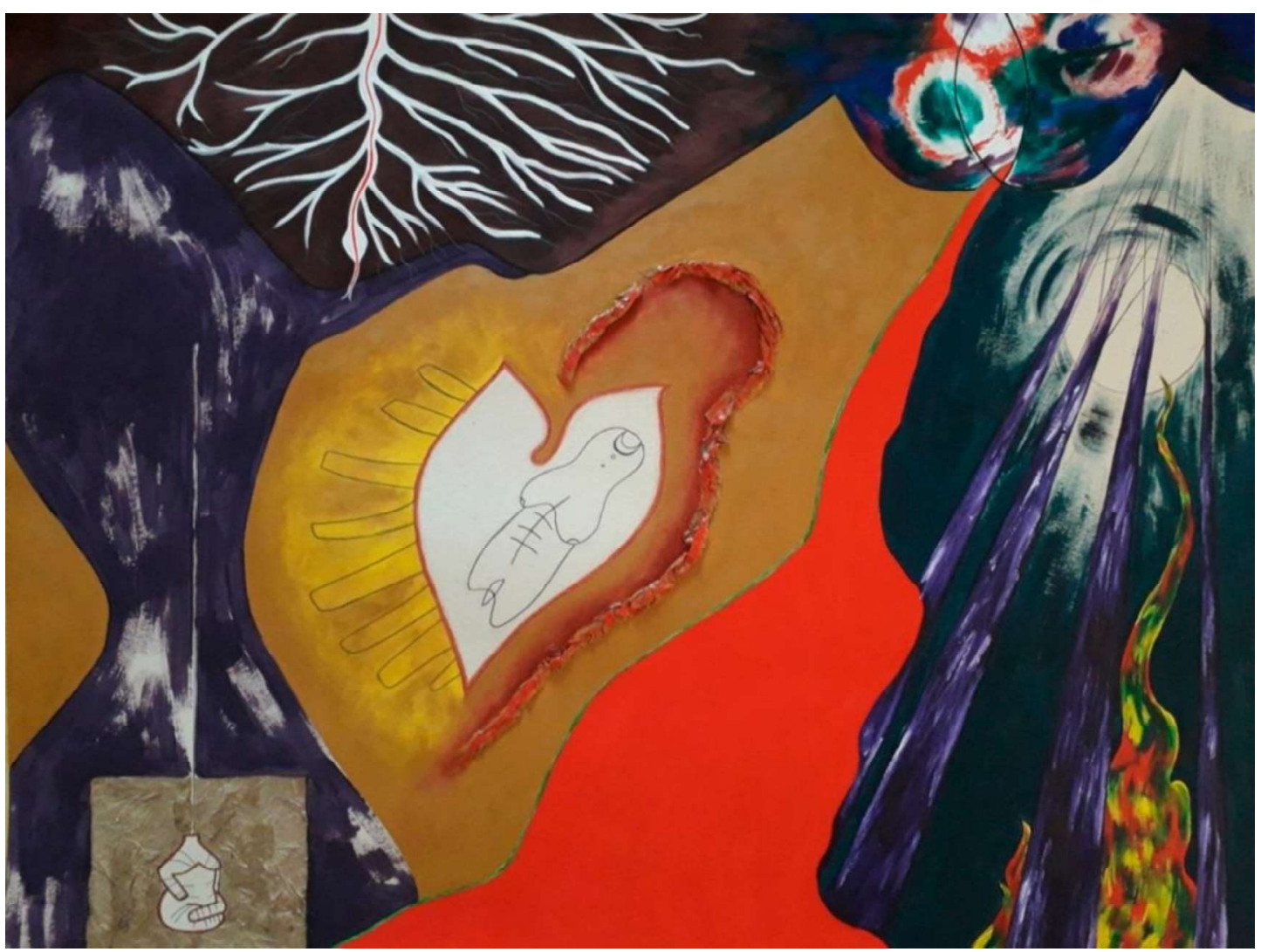

Figura 5

Jacqueline Amadio de Abreu, Transformação de um sistema que volta ao seu estado inicial, 2019, pintura a guache e a óleo, desenho e colagem sobre papel paraná, 80 x $100 \mathrm{~cm}$.

Explorei esse corpo-experiência por meio de fragmentos e símbolos na composição: o sangue-vida, vermelho, símbolo da menstruação; a forma, que remete à abertura da vagina; a experiência do corpo em dança em torno do fogo, simbolizado pela fogueira que transcende até o céu; a vênus, que é retomada de forma ressignificada, remetendo ao pré-patriarcal, dentro das discussões de reapropriação; a serpente, com seu poder sexual e criativo; a lua, com sua força cíclica e ritualística; o traço, a linha, com sua potência de não representação. Há, também, as formas e cores que dão pistas sobre a relação do corpo com a 
natureza: aparecem na terra; nas cores do fogo, do céu e dos oceanos; na silhueta das folhas; nas formas das árvores e das raízes. É daí que os corpos vêm: da origem do mundo, da relação com a terra. O corpo está presente e se tece em todos esses símbolos, formas e cores que compõem um corpo-experiência.

A composição da pintura é feita por esses elementos distintos que fazem sentido em si, mas que ganham perspectiva em conjunto, pois a atmosfera da obra e cada elemento se unem e criam sentidos e significações. O processo foi essa dança de um espaço a outro; dos contrastes de formas e cores; das significações que foram sendo construídas durante o movimento da criação e que continuarão significando sob o olhar de cada espectador que se abrir à obra.

Das minhas experimentações e pesquisas com pintura, sou afetada por outras mulheres e artistas. Encontro Mendieta nesse retorno à natureza em minha pintura. Vejo Muholi na tinta vermelha que remete ao sangue. Há vestígios de Chicago no símbolo da Vênus, que é representada de forma ressignificada e remete ao pré-patriarcal. Percebo Riemer na celebração dos elementos com o corpo. E essa é outra potência da estética feminista: ela afeta outras mulheres, permite a voz, abre possibilidades. Podemos nos ver em novos lugares, escritas e visualidades, reconstruindo junto, criando junto.

A superação da subjetividade de gênero significa necessariamente uma transformação das sensibilidades, das relações e dos afetos. Ou seja, a desarticulação da reprodução do simbolismo que estrutura a dominação masculina a partir da noção de gênero - baseada na discussão em torno do corpo anatômico como exemplifica Bourdieu - pode constituir uma chave para fazer emergir aquilo que Deleuze \& Guattari denominam devirmulher, algo que coloca em questão o masculino como medida, mas que 
pode implicar ainda uma crítica a todas as medidas e padrões simbólicos presentes na sociedade ${ }^{50}$.

O nomadismo feminista marca o itinerário político específico das mulheres que apoiam a pluralidade, a multiplicidade, a complexidade, a diversidade, o não binarismo e a não hierarquização. “Feministas nômades visam desfazer as estruturas de poder que sustentam as oposições dialéticas dos sexos, enquanto respeitam a diversidade das mulheres e a multiplicidade dentro de cada mulher"51. $\mathrm{O}$ feminismo briga com as estruturas de poder e, junto com isso, possui a força necessária para ressignificar.

Arthur Coleman Danto mostra que essa multiplicidade aparece nesse período de produtividade experimental contemporânea no campo das artes visuais, no qual não há uma única direção narrativa, mas diversas, em que outras não são excluídas nem estabilizadas como normas. ${ }^{52} \mathrm{~A}$ arte contemporânea se apresenta, então, em uma base ética, possui um compromisso ético com as múltiplas narrativas.

É nisso que consiste a experiência estética do mundo: ela depende da capacidade do corpo de fazer-se vulnerável a seu entorno, deixando-se tomar pela sensação da disparidade entre as formas da realidade e os movimentos que se agitam sob sua suposta estabilidade, o que coloca o corpo em estado de arte $^{53}$.

A arte como potencialidade de vida é uma afirmação, é um território para criar e coexistir todas as formas de vida, de forma ética e múltipla. Os estudos pela arte contemporânea possibilitam abordar essa multiplicidade e essa diversidade

\footnotetext{
${ }^{50}$ Rosi Marie Santini e Joana Camelier, "Devir mulher, sexualidade e subjetividade: aproximações entre Deleuze \& Guattari e Pierre Bourdieu sobre a construção social dos corpos", 2015, p. 107.

${ }^{51}$ Rosi Braidotti, Op. Cit., 2002, p. 14, grifo do autor.

${ }^{52}$ Arthur Coleman Danto, Após o fim da arte: a arte contemporânea e os limites da história, 2006, p. 16.

${ }^{53}$ Suely Rolnik, Arquivo para uma obra acontecimento, 2011, p. 24, grifo do autor.
} 
que buscamos, para que possamos viver mais livres. Os estudos feministas andam de mãos dadas com esse compromisso ético. E é dessa forma que, por meio da arte, há novas figurações ao corpo e à subjetividade feminina, que dançam por horizontes mais livres, afirmativos e singulares. São inúmeras as mulheres artistas que criam por esse devir-mulher, com trabalhos muito potentes. Aqui, vimos o trabalho de quatro delas, Zanele Muholi, Elisa Riemer, Ana Mendieta e Judy Chicago, artistas de diferentes nacionalidades, raças e sexualidades, que transformam narrativas e recriam imaginários. Vimos, ainda, o meu próprio trabalho, em diálogo com essas artistas.

Iniciamos este trabalho com as palavras de Janaina Matter, com um eu sinto muito pelas histórias apagadas; entretanto, nos direcionamos ao fim desta escrita carregadas de contribuições e de possibilidades que a arte nos permite. Partimos daqui com um repertório maior de caminhos retraçados por mulheres, que nos direcionam a modos de subjetivação livres e inventivos, que nos guiam pelo devir-mulher para operar em nosso existir, para fazer nossas vidas potentes.

Eu te busco nas profundezas do mar. Sem ar eu vou e volto só com a gana de te encontrar. Das cinzas reconstruo seu corpo, mesmo que leve uma vida inteira para dá-lo de volta a você, ou mais. As lâminas que te golpeiam quebram todas em contato com sua pele, que agora é revestida com a pele de todas as mulheres que já passaram por esse mundo. Os objetos e mãos que te sufocam servem agora para ecoar seu grito, sua voz. Se é bala de revólver que te leva, eu a torno doce, para que possa chupá-la e se deleitar de açúcar. $O$ veneno que te paralisa é agora remédio para sua angústia, gosto de cuidar para que sempre o seja. Eu posso te ninar no colo sempre que você precisar, criança ou não e ouvir sobre suas feridas, que ardem, rasgam, queimam... e posso ser artista, te cantar uma canção, te ler um poema, te desenhar, te dançar, te trazer ao teatro ${ }^{54}$.

\footnotetext{
${ }^{54}$ Janaina Matter, “Com água de conforto”, 2019, p. 30, grifo nosso.
} 
A direção ética que atua nos trabalhos dessas mulheres artistas é o compromisso de tecer relações entre arte-corpo-vida, cada uma ao seu modo e com sua linguagem, mas tendo em comum a evidência do corpo em experiência e na relação com o outro. São mulheres com potência criativa e que a usam para falar e possibilitar a voz. Elas ressignificam narrativas, retomam histórias, dão visibilidade a outras mulheres, tecem outras significações sobre os corpos, em uma perspectiva mais libertária. São trabalhos que nos fazem refletir e ampliar um imaginário feminino mais livre e múltiplo. A arte que brota do devir-mulher é também o próprio meio para esse devir e gera figurações outras que marcam as narrativas e as visualidades de histórias e vidas de mulheres criadas e vivenciadas por nós.

\section{Referências}

ALMEIDA, Flávia Leme de. Mulheres recipientes: recortes poéticos do universo feminino nas artes visuais. São Paulo: Cultura Acadêmica, 2010.

BRAIDOTTI, Rosi. Diferença, diversidade e subjetividade nômade. Revista Labrys - estudos feministas, Brasília, n. 1-2, p. 1-15, dez. 2002.

BRANCO, Guilherme Castelo. Anti-individualismo, vida artista: uma análise não-fascista de Michel Foucault. In: VEIGA-NETO, Alfredo; RAGO, Margareth (Orgs.). Para uma vida não-facista. Belo-Horizonte: Autêntica Editora, 2009.

CATTANI, Icleia Borsa. Icleia Cattani. Rio de Janeiro: FUNARTE, 2004. 
CHICAGO, Judy. A mulher como artista (1971). In: PEDROSA, Adriano; MESQUITA, André (Orgs.). História da sexualidade: antologia. São Paulo: MASP, 2018.

DANTO, Arthur Coleman. Após o fim da arte: a arte contemporânea e os limites da história. Tradução de Saulo Krieger. São Paulo: Odysseus Editora, 2006.

HAINOSZ, Ana Gabriela Portelinha. Da representação para a auto apresentação das mulheres nas artes visuais. 2018. 64f. Trabalho de conclusão de curso (Licenciatura em Artes Visuais) - Universidade Estadual de Maringá, Maringá, PR, 2018.

KRAHEI, Inês Bueno; MATOS, Sônia Regina da Luz. Devir-mulher como diferença. In: CONGRESSO INTERNACIONAL DE FILOSOFIA E EDUCAÇÃO (CINFE), 5., 2010, Caxias do Sul. Anais... Caxias do Sul, 2010. Disponível em: https://www.ucs.br/ucs/eventos/cinfe/artigos/arquivos/eixo_tematico3/Devir

mulher\%20como\%20diferenca.pdfhttps://www.ucs.br/ucs/eventos/cinfe/arti gos/artigos. Acesso em: 31 out. 2019.

LAURENTIIS, Gabriela de. Fazer e desfazer formas: as imagens do feminino na arte de Louise Bourgeois. In: RAGO, Margareth; MURGEL, Ana Carolina Arruda de Toledo (Orgs.). Paisagens e tramas: o gênero entre a história e a arte. São Paulo: Intermeios, 2013.

MATTER, Janaina. Com água te conforto. In: MATTER, Janaina. Mulher como você se chama?Paraná: Súbita Companhia de Teatro, 2019. 
NOCHLIN, Linda. Por que não houve grandes mulheres artistas?Tradução de Juliana Vacaro. São Paulo: Edições Aurora, 2016.

PRIORI, Claudia. Mulheres e a pintura paranaense: relação entre arte e gênero. História: Questões \& Debates, Curitiba, v. 65, n.1, p. 359-384, jan./jul. 2017.

RAGO, Margareth. Feminismo e subjetividade em tempos pós-modernos. In: COSTA, Claudia Lima; SCHMIDT, Simone Pereira (Orgs.). Poéticas e Políticas Feministas. Florianópolis: Editora das Mulheres, 2004.

ROLNIK, Suely. Arquivo para uma obra acontecimento. São Paulo: SESC SP, 2011.

ROLNIK, Suely. Uma insólita viagem à subjetividade: fronteiras com a ética e a cultura. 1997. Disponível em:

http://www.caosmose.net/suelyrolnik/pdf/sujeticabourdieu.pdf. Acesso em: 26 abr. 2019.

SANTINI, Rose Marie; CAMELIER, Joana. Devir mulher, sexualidade e subjetividade: aproximações entre Deleuze \& Guattari e Pierre Bourdieu sobre a construção social dos corpos. Revista Ártemis, v. 19, p. 101-108, jan./jul. 2015.

SILVA, Rosane Neves da. A dobra deleuziana: o mundo como potência de invenção. In: FONSECA, Tania Mara Galli; ENGELMAN, Selda (Orgs.). Corpo, Arte e Clínica. Porto Alegre: UFRGS, 2004.

STUBS, Roberta. A/r/tografia de um corpo-experiência: arte contemporânea, feminismos e produção de subjetividade. 2015. 276f. Tese 
(Doutorado em Psicologia) - Faculdade de Ciências e Letras, Universidade Estadual Paulista, Assis, SP, 2015.

STUBS, Roberta. Devires de um corpo experiência. Curitiba: Appris, 2019.

TVARDOVSKAS, Luana Saturnino. Dramatização dos corpos: arte contemporânea e crítica feminista no Brasil e Argentina. São Paulo: Intermeios, 2015.

TVARDOVSKAS, Luana Saturnino. Fabulações de si na arte contemporânea: Ana Miguel, Rosana Paulino e Cristina Salgado. In: RAGO, Margareth; MURGEL, Ana Carolina Arruda de Toledo (Orgs.). Paisagens e tramas: o gênero entre a história e a arte. São Paulo: Intermeios, 2013.

TVARDOVSKAS, Luana Saturnino. Figurações feministas na arte contemporânea: Márcia X., Fernanda Magalhães e Rosângela Rennó. 2008. 220f. Dissertação (Mestrado em História) - Universidade Estadual de Campinas, Instituto de Filosofia e Ciências Humanas, Campinas, SP.

\section{Referência para citação deste artigo}

ABREU, Jacqueline Amadio de; STUBS, Roberta. Pensando as figurações feministas e o devir-mulher a partir da arte. Revista PHILIA | Filosofia, Literatura \& Arte, Porto Alegre, volume 2, número 2, p. 269 - 301, novembro de 2020. 